\title{
Necrólise epidérmica tóxica associada ao lúpus eritematoso sistêmico: um relato de caso
}

\section{Toxic epidermal necrolysis associated with systemic lupus erythematosus: a case report}

Maria Fernanda Palermo da Silva' • Rosane de Paula Codá ${ }^{2}$ Luis Augusto Carrera Louzada ${ }^{3}$
Wânia de Oliveira Vianna ${ }^{4}$. Ghislaine de Mattos Ferreira Faria ${ }^{5}$ Márcia Veríssimo de Souza

RESUMO

Objetiva-se descrever o caso clínico de uma paciente com Necrólise Epidérmica Tóxica, tendo como enfoque o acompanhamento da evolução das lesões cutâneas; discutir o acompanhamento da evolução da doença e o uso das coberturas disponíveis para a realização dos curativos; e analisar a eficácia do tratamento empregado com Polihexanidabetaina (PHMB) e placas de hidrofibra com prata. Trata-se de um relato de caso realizado em um hospital federal do estado do Rio de Janeiro sob autorização por escrito da paciente. $O$ curativo era realizado diariamente, pela Comissão Terapêutica de Feridas (CTF) e médicos da Cirurgia Plástica. No curativo do corpo, que apresentava áreas com descolamento total da epiderme e muito friáveis inicialmente foi utilizada como cobertura primária Sulfadiazina de prata a $1 \%$. Conduta que foi mantida por 07 dias, não havendo melhora aparente do quadro. Foi então realizada antissepsia com o PHMB e utilizadas placas de hidrofibra em todo o corpo. Após 15 dias, na terceira troca do curativo, evidenciou-se melhora significativa, não sendo necessário uso de hidrofibra. Concluí-se que ficou clara a eficácia do tratamento empregado e evidente a importância do uso da cobertura adequada para cada demanda, sendo vantajoso e benéfico para todas as partes envolvidas.

Palavras-chave: Doenças Autoimunes; Lúpus Eritematoso Sistêmico; Ferimentos e Lesões.

\begin{abstract}
The aim is to describe the clinical case of a patient with Toxic Epidermal Necrolysis focusing on the evolution of cutaneous lesions; to discuss the disease progression and the use of covers available for the curative; and to analyze the effectiveness of the treatment employed with Polihexanide Betaine Solution (PHMB) and Hydrofiber plates with Silver. This is a case report held in a federal hospital in the state of Rio de Janeiro. The patient in question authorized this report through The Free Informed Consent Form, according to Resolution 466/12. The curative was performed daily, in the Surgical Center by the Therapeutic Committee of Wounds (TCW) and Medical Plastic Surgery. In the body curative, which presented areas with complete detachment of the epidermis initially friable was performed primary cover with Silver Sulfadiazine 1\% cream. This conduct was maintained for 07 days. There was no apparent improvement. Then antisepsis was performed with PHMB and was used plates throughout the body. After 15 days, in the third dressing exchange, a significant improvement was evidenced, not requiring the use of Hydrofiber. It concludes that the efficacy of the treatment used was clear and it is evident the importance of using the appropriate coverage for each demand, being advantageous and beneficial to the patient, the teams involved and the institution.
\end{abstract}

Keywords: Autoimmune Diseases; Lupus Erythematosus, Systemic; Wounds and Injuries.

NOTA

Enfermeira. Residente em Oncologia no Instituto Nacional de Câncer José Alencar Gomes da Silva; especialista em Enfermagem Dermatológica pela Universidade Estácio de Sá; pósgraduada em enfermagem clínica e cirúrgica no Hospital Federal dos Servidores do Estado do Rio de Janeiro/ Universidade Federal do Estado do Rio de Janeiro. E-mail: mfps29@gmail.com ${ }^{2}$ Enfermeira. Mestranda em Saúde e Tecnologia no Espaço Hospitalar (UNIRIO); especialista em Enfermagem Dermatológica pela Universidade Gama Filho; membro da Câmara Técnica de Feridas do Ministério da Saúde do Rio de Janeiro; coordenadora da Comissão Terapêutica de Feridas do Hospital Federal dos Servidores do Estado do Rio de Janeiro.E-mail: rosanecoda@gmail.com

${ }^{3}$ Enfermeiro. Pós-graduado em enfermagem clínica e cirúrgica no Hospital Federal dos Servidores do Estado do Rio de Janeiro/ Universidade Federal do Estado do Rio de Janeiro. E-mail: luis.acl.enfermeiro@gmail.com

${ }^{4}$ Enfermeira. Especialista em Enfermagem Dermatológica; membro da Câmara Técnica de Feridas do Ministério da Saúde do Rio de Janeiro; membro da Comissão Terapêutica de Feridas do Hospital Federal dos Servidores do Estado do Rio de Janeiro. E-mail: waniavianna@hotmail.com

${ }^{5}$ Enfermeira. Especialista em Acessos Vasculares e Terapia Infusional pelo Instituto de Ensino do Hospital Israelita Albert Einstein; membro da Superintendência de Vigilância Sanitária do Estado do Rio de Janeiro; membro da Comissão Terapêutica de Feridas no Hospital Federal dos Servidores do Estado do Rio de Janeiro; docente no curso de pósgraduação em Pediatria e Neonatologia da Universidade Estácio de Sá; docente na empresa Novare Assessoria e Capacitação Profissional; docente no Consórcio Brasileiro de Acreditação (CBA).E-mail: ghislainemattos@gmail.com.br

${ }^{6}$ Enfermeira. Especialista em Enfermagem Neonatal pela Universidade do Estado do Rio de Janeiro; especialista em Enfermagem Dermatológica pela Universidade Gama Filho; coordenadora de Enfermagem no Serviço de Hemoterapia do Hospital Universitário Antônio Pedro; membro da Comissão Terapêutica de Feridas do Hospital Federal dos Servidores do Estado do Rio de Janeiro.E-mail: marciaverissimo.enf@gmail.com 


\section{INTRODUÇÃO}

Sabe-se que o lúpus é uma doença autoimune e como tal resulta em prejuízos graves para a saúde e qualidade de vida do paciente. Outra doença autoimune que resulta em grande agressão física é a Necrólise Epidérmica Tóxica (NET), uma patologia cutânea que possui como característica principal a descamação extensa da pele sendo sua toxicidade sistêmica ${ }^{1-2}$.

A NET é uma patologia cutânea com baixa incidência, porém com alta morbimortalidade 3 . Caracteriza-se por esfoliação cutânea extensa, toxicidade sistêmica e febre alta. Sua deflagração relaciona-se classicamente por reação imunogênica induzida por fármacos, ainda que também haja relatos de origem idiopática ou por reação enxerto-versus-hospedeiro ${ }^{1}$.

Primeiramente, essas lesões assumem forma macular com centro escurecido e borda irregular, transformandose em flictenas que se confluem para grandes áreas necrosadas não aderentes a derme, onde uma leve pressão resulta de seu desprendimento (sinal de Nikolsky). A derme exposta altamente exsudativa representa grande risco de infecção séptica e desequilíbrio hidroeletrolítico. Anterior à NET, verificamos a presença de lesão em mucosas, especialmente por aquelas formadas por epitélio pavimentoso estratificado (conjuntiva, orofaringe, mucosa nasal, esôfago, uretra, vagina, anus e períneo) ${ }^{1}$.

Otratamento desta patologia é equivalente ao observado ao grande queimado, sendo muitas vezes encaminhados a Unidades de Queimados. As metas do tratamento incluem: retirada da exposição ao agente causal, prevenção da sepse, controle hidroeletrolítico e nutricional, controle da dor eficaz, prevenção das complicações oftalmológicas e, curativo adequado 3 .

Quando associados, o Lúpus e a NET podem ser ainda mais fatais para o paciente, uma vez que há uma combinação de duas patologias brutais e severas. Portanto o cuidado ao paciente acometido por essas doenças deve ser integral, multiprofissional e interdisciplinar. 0 tratamento empregado deve ser bem planejado e constantemente avaliado, uma vez que este deve ser tanto local quanto sistêmico ${ }^{3}$.

O enfermeiro que atua na assistência deste paciente deve ser devidamente capacitado, conhecer o tratamento empregado, as técnicas a serem utilizadas e estar também atualizado quanto às coberturas existentes no mercado, a fim de ser efetivo no tratamento escolhido.

A questão que norteou este estudo foi: qual a eficácia e o benefício do uso de determinadas coberturas no tratamento das lesões de NET?

Sendo assim, este estudo teve como objetivos: descrever o caso clínico de uma paciente com Necrólise Epidérmica Tóxica, tendo como enfoque o acompanhamento da evolução das lesões cutâneas; discutir o acompanhamento da evolução da doença e o uso das coberturas disponíveis para a realização dos curativos; e analisar a eficácia do tratamento empregado com Polihexanida-betaina (PHMB) e placas de hidrofibra com prata.

\section{MÉTODO}

0 presente trabalho trata-se de uma pesquisa descritiva do tipo estudo de caso. O levantamento dos dados foi realizado no ano de 2015, em um hospital do Rio de Janeiro, a partir de informações coletadas em prontuário e também vivenciadas pelas pesquisadoras. Em atendimento à Resolução 466/12/CNS/MS', a pesquisa foi realizada mediante preenchimento do Termo de Consentimento Livre e Esclarecido pela paciente, depois de informada sobre os objetivos da pesquisa e a manutenção do sigilo sobre sua identidade.

Os dados pessoais e de história da doença atual e pregressa foram coletados do prontuário da paciente no período em que esta permanecia internada em tratamento. A descrição do caso foi realizada com base na vivência dos enfermeiros pesquisadores deste estudo (enfermeiras especialistas da Comissão Terapêutica de Feridas-CTF e enfermeiros residentes), uma vez que estes atuaram no caso. 0 acompanhamento da paciente pela CTF se deu no período de 24/08/2015 a 28/09/2015, desde a solicitação do parecer até a alta hospitalar.

Os dados foram agrupados e ordenados conforme cronologia dos fatos para serem, então, analisados, visando identificar a partir de que momento houve evolução clínica positiva da paciente e possibilitando assim, identificar a cobertura que levou a este resultado.

\section{RELATO DE CASO}

Mulher, 30 anos, parda, casada, cristã, cuidadora de crianças, ensino primário incompleto, nascida e residente em Duque de Caxias. Em seu histórico patológico pregresso apresentou fotossensibilidade, rash malar, aftas orais, alopécia e poliartrite sistêmica cumulativa de pequenas e grandes articulações, relato de linfonodomegalia axilar, tendo permanecido internada por três dias em janeiro de 2015 e recebido alta devido melhora do quadro articular. Em fevereiro do mesmo ano evoluiu com piora do quadro cutâneo com eritrodermia difusa, descamação e algumas bolhas crostosas, sendo iniciado acompanhamento hospitalar. Após hipótese diagnóstica pela dermatologia de Lúpus agudo, iniciou hidroxicloroquina $400 \mathrm{mg}$ e prednisona $60 \mathrm{mg}$. Nos exames prévios à internação, apresentou $\operatorname{lgG}$ e IgM positivos para Citomegalovírus.

Novamente internada em agosto de 2015, na enfermaria de Clínica Médica, por solicitação do serviço de Dermatologia, com relato de que após exposição solar iniciou vermelhidão no corpo evoluindo, em três dias, para descolamento da epiderme do tronco, abdome e membros. E dois dias depois, surgiram lesões em mucosa oral e vulvar. Foi diagnosticada pela equipe médica com 
Necrólise Epidérmica Tóxica. A paciente possuía cateter vesical de demora e cateter retal, visando principalmente reduzir o risco de infecção devido contato de eliminações fisiológicas com toda área exposta sem epiderme.

Foi solicitado parecer da CTF, que iniciou o acompanhamento da paciente que ao exame apresentava lesões hiperemiadas e escamativas por todo o corpo e bolhas em abdome, bem como se queixava de dor pelo atrito com a cama. 0 calcâneo esquerdo apresentava úlcera por pressão (UPP) com presença de tecido necrótico e o membro superior direito (MSD), onde desenvolveu uma vasculite, apresentava também regiões contendo necrose.

Os atuantes nos curativos foram a CTF, o Serviço de Cirurgia Plástica e Reparadora (CPR) e residentes de Enfermagem.

Nos primeiros 10 dias os curativos foram realizados diariamente no Centro Cirúrgico Geral (CC) contando com uma equipe de anestesistas para realizar a sedação da paciente (com Citrato de Fentanila, Cloridrato de Cetamina e Midazolam). Na face foi recomendado uso de óleo a base de Ácidos Graxos Essenciais - AGE 03 vezes ao dia, conduta que foi mantida até a total epitelização da área, pois foi notada uma boa evolução.

Desde o inicio da atuação da CTF, houve solicitação por parte desta para que a direção do hospital efetuasse a compra de material específico para o curativo da paciente, caso contrário seria necessária transferência da mesma para um Centro de Tratamento de Queimados, uma vez que o caso era comparado a um grande queimado. Sendo assim, a Instituição efetuou a compra das coberturas solicitadas e os curativos subsequentes foram realizados com placas de hidrofibra absorvente com prata e solução de Polihexanida-betaina (PHMB), sendo então observada efetiva melhora da paciente.

\section{DISCUSSÃO}

Foram descritas as coberturas utilizadas pela equipe na realização dos curativos da paciente do caso em questão com seus respectivos mecanismos de ação e indicações, como verifica-se no quadro 1.

Nos primeiros curativos da paciente, como demonstrado na figura 1 , foi utilizada Sulfadiazina de prata $1 \%$, pois era a cobertura disponível mais apropriada para o caso, uma vez que possui ação bactericida e bacteriostática e, segundo Santos Neto et al.,"a ferida deve ser monitorizada para infecções, já que seu aparecimento é comum e uma grande causa de mortalidade nesses pacientes"”.

Por orientação dos serviços de Dermatologia e Reumatologia, modificou-se a cobertura sendo utilizado AGE (11 frascos de $200 \mathrm{ml}$ ), apesar de não haver concordância por parte da CTF. No dia seguinte, toda a área se apresentava ainda mais friável e com odor fétido. O AGE é muito mais indicado para uso em pele íntegra, não possuindo forte evidência científica quanto à sua ação antimicrobiana e efetividade na cicatrização de feridas sem

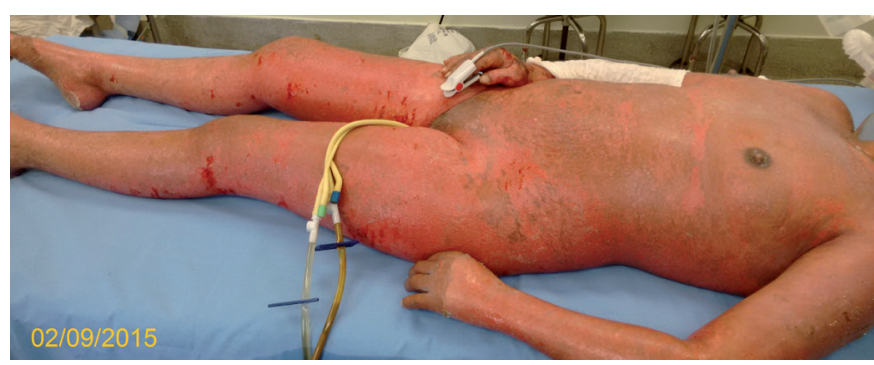

Figura 1: Superfície corporal completamente friável. Rio de Janeiro, RJ, Brasil, 2015

Fonte: Silva M FP, et al. Necrólise Epidérmica Tóxica associada ao Lúpus Eritematoso Sistêmico: um relato de caso.

associação com outras coberturas ${ }^{8-9}$. Portanto se retomou a conduta anterior, com Sulfadiazina, porém sem melhora aparente.

Quando houve disponibilidade da cobertura solicitada o curativo foi realizado irrigando todo o corpo com a solução de PHMB (05 frascos de $350 \mathrm{ml}$ ), permanecendo por 10 minutos com compressas estéreis. Depois de retiradas as compressas, foram colocadas as placas de hidrofibra em toda a extensão corporal com exceção da face, sendo utilizadas 86 placas de $15 \times 15 \mathrm{~cm}$, como verifica-se na figura 2 .

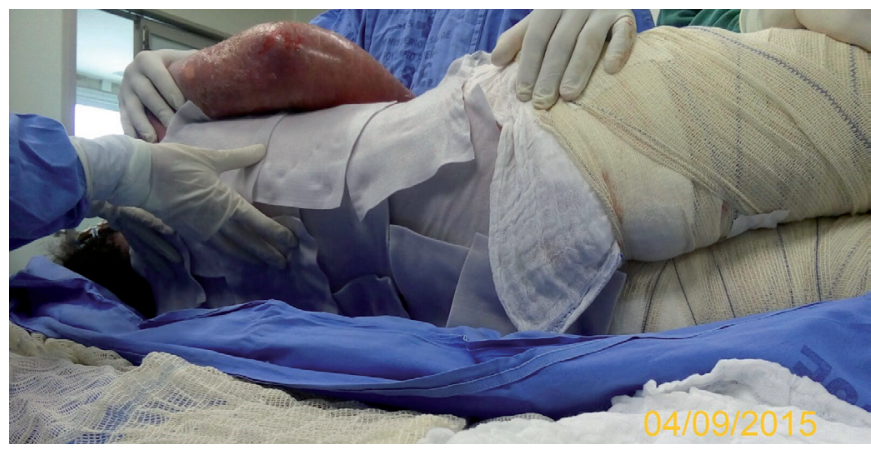

Figura 2: Aplicação das placas de hidrofibra com prata. Rio de Janeiro, RJ, Brasil, 2015

Fonte: Silva M FP, et al. Necrólise Epidérmica Tóxica associada ao Lúpus Eritematoso Sistêmico: um relato de caso.

Além de esta cobertura apresentar como benefícios o vasto poder de absorção e contenção de odor e infecção, possibilita a troca em até 07 dias o que promove um maior conforto para a paciente, já que dispensa a realização constante de todo o procedimento feito diariamente ${ }^{5-10}$. Sendo assim, após 06 dias foi realizada a troca.

Optou-se pela realização do curativo no leito da paciente no CTI onde não foi necessária sedação, apenas analgesia com $2 \mathrm{mg}$ de Sulfato de Morfina intravenoso. Com a retirada do curativo anterior era notável a evolução positiva das lesões, como demonstrado na figura 3 .

Foi realizado o procedimento igualmente ao anterior, no entanto foram utilizados 02 frascos de PHMB, e não foi necessário ocluir todo o corpo, tendo sido utilizadas apenas 18 placas de hidrofibra. A face já não apresentava mais nenhuma crosta estando epitelizada e levemente hiperemiada, dando continuidade ao uso de AGE. O cateter retal havia sido retirado, 
Quadro 1. Descrição das coberturas utilizadas. Rio de Janeiro, RJ, Brasil, 2016

\begin{tabular}{|c|c|c|c|c|}
\hline Cobertura & Descrição & Mecanismos de ação & Indicações & Observações \\
\hline $\begin{array}{l}\text { Ácidos Graxos } \\
\text { Essenciais (5) }\end{array}$ & $\begin{array}{l}\text { São compostos de } \\
\text { ácidos linoleico e } \\
\text { alfa-linolênico, e sua } \\
\text { apresentação é na forma } \\
\text { oleosa. }\end{array}$ & $\begin{array}{l}\text { Favorece a nutrição celular e } \\
\text { hidrata a pele de forma intensiva, } \\
\text { formando uma película protetora; } \\
\text { protege a pele de abrasões e } \\
\text { escoriações. }\end{array}$ & $\begin{array}{l}\text { Utilizado na pele } \\
\text { íntegra, visando à } \\
\text { prevenção de lesões. }\end{array}$ & $\begin{array}{l}\text { Relato de uso em } \\
\text { feridas abertas, } \\
\text { limpas ou infectadas, } \\
\text { e no tratamento de } \\
\text { queimaduras. }\end{array}$ \\
\hline $\begin{array}{l}\text { Espuma com } \\
\text { prata (5) }\end{array}$ & $\begin{array}{l}\text { Curativo estéril, } \\
\text { apresentado em placas } \\
\text { de material celulósico, } \\
\text { formadas por filme } \\
\text { semipermeável do } \\
\text { poliuretano, com } \\
\text { componente interno de } \\
\text { carboximetilcelulose } \\
\text { sódica, e adição de um } \\
\text { componente ativo de } \\
\text { prata inorgânica. }\end{array}$ & $\begin{array}{l}\text { Promove o meio úmido, possui } \\
\text { atividade antibacteriana, absorve } \\
\text { exsudato, diminui o odor e reduz o } \\
\text { risco de infecção. }\end{array}$ & $\begin{array}{l}\text { Feridas estagnadas } \\
\text { em todas as fases } \\
\text { de cicatrização, com } \\
\text { moderada a alta } \\
\text { exsudação, abrasões, } \\
\text { queimaduras, úlceras } \\
\text { diabéticas, feridas } \\
\text { pós-operatórias, áreas } \\
\text { doadoras de pele, } \\
\text { úlceras por pressão, } \\
\text { úlceras de perna. }\end{array}$ & $\begin{array}{l}\text { Troca em até } 7 \text { dias ou } \\
\text { quando saturado. }\end{array}$ \\
\hline Hidrogel (5) & $\begin{array}{l}\text { Composto transparente } \\
\text { e incolor formado } \\
\text { por: água (77,7\%), } \\
\text { carboximetilcelulose } \\
(2,3 \%) \text { e propilenoglicol } \\
(20 \%)\end{array}$ & $\begin{array}{l}\text { Ao entrar em contato com o } \\
\text { exsudato, aumenta seu volume, } \\
\text { porém não se dissolve. }\end{array}$ & $\begin{array}{l}\text { É indicada para feridas } \\
\text { com perda tecidual } \\
\text { superficial ou profunda } \\
\text { parcial, feridas com } \\
\text { tecido necrótico, áreas } \\
\text { doadoras de pele, } \\
\text { queimaduras de } 1^{\circ} \text { e } 2^{\circ} \\
\text { graus, radiodermites e } \\
\text { dermoabrasões. }\end{array}$ & $\begin{array}{l}\text { É uma cobertura } \\
\text { não aderente, } \\
\text { necessitando de } \\
\text { cobertura secundária. } \\
\text { Contraindicada para } \\
\text { feridas cirúrgicas } \\
\text { fechadas, feridas } \\
\text { com muito exsudato } \\
\text { (pelo fato de não } \\
\text { ter capacidade de } \\
\text { absorção) ou feridas } \\
\text { colonizadas por fungos } \\
\text { e pele íntegra. }\end{array}$ \\
\hline $\begin{array}{l}\text { Polihexametil- } \\
\text { biguanida (6) }\end{array}$ & $\begin{array}{l}\text { Solução de irrigação } \\
\text { de feridas composta } \\
\text { por } 0,1 \% \text { de } \\
\text { undecilaminopropil } \\
\text { betaína, } 0,1 \% \text { de } \\
\text { polihexanida e } 99.8 \% \text { de } \\
\text { água purificada. }\end{array}$ & $\begin{array}{l}\text { Remove revestimentos, biofilmes, } \\
\text { prepara o leito da ferida para } \\
\text { receber curativo. }\end{array}$ & $\begin{array}{l}\text { Indicado para feridas } \\
\text { de espessura parcial } \\
\text { a total, úlceras por } \\
\text { pressão de estágio I } \\
\text { a IV, úlceras arteriais, } \\
\text { venosas e mistas, } \\
\text { úlceras pós-cirúrgicas, } \\
\text { queimaduras de } 1^{\circ} \text { e } 2^{\circ} \\
\text { graus, áreas doadoras } \\
\text { de enxerto, úlceras } \\
\text { infectadas ou não. }\end{array}$ & $\begin{array}{l}\text { Contraindicação: } \\
\text { Queimaduras grau III } \\
\text { e IV; Aplicação em } \\
\text { carlilagem hialina. }\end{array}$ \\
\hline $\begin{array}{l}\text { Sulfadiazina de } \\
\text { prata 1\% (5) }\end{array}$ & $\begin{array}{l}\text { Creme contendo } \\
\text { sulfadiazina de prata } \\
1 \%\end{array}$ & $\begin{array}{l}\text { O íon de prata em veículo cremoso } \\
\text { causa precipitação de proteínas } \\
\text { e age diretamente na membrana } \\
\text { citoplasmática da célula bacteriana, } \\
\text { exercendo ação bactericida } \\
\text { imediata e ação bacteriostática } \\
\text { residual, promovida pela liberação } \\
\text { gradativa de pequenas quantidades } \\
\text { de prata iônica. }\end{array}$ & $\begin{array}{l}\text { Indicado para } \\
\text { queimaduras em } \\
\text { geral, para prevenir a } \\
\text { colonização, e também } \\
\text { para lesões crônicas, de } \\
\text { natureza vascular. }\end{array}$ & $\begin{array}{l}\text { Pode ser associada ao } \\
\text { ácido hialurônico e a } \\
\text { outros componentes. }\end{array}$ \\
\hline
\end{tabular}

Fonte: 5-Guimarães MCSS e Geovanini T. ; 6-Laboratórios B. Braun

devido mudança na dieta ofertada, aumentando a demanda proteica, o que ocasionou uma eliminação de fezes moldadas.

Em cinco dias, na troca do curativo, pôde-se notar novamente boa evolução, como na figura 4. Apenas a região glútea apresentava-se friável e o MSD ainda com presença de tecido necrótico. Optou-se por encaminhar a paciente para banho de aspersão em cadeira higiênica. Foi aplicado, após o banho, creme de uréia em todo o corpo da paciente, com exceção das áreas ainda lesionadas, onde foi aplicada, antes da cobertura, solução de PHMB $(\approx 20 \mathrm{ml})$. Em região glútea foram utilizadas 02 placas de hidrofibra. Em MSD, utilizou-se 01 placa de hidrofibra associado à hidrogel. $\mathrm{Na}$ UPP em calcâneo esquerdo foi utilizado hidrogel. A face apresentava-se epitelizada e corada, sendo utilizado creme hidratante para proteção cutânea. Foi ainda sugerida pela CTF a retirada do cateter vesical, encaminhamento diário da paciente ao banho de aspersão e uso de comadre para realização das eliminações fisiológicas quando esta não fosse possível no sanitário. Foi também reforçada, novamente, a solicitação de fisioterapia para a paciente, uma vez que esta apresentava progressiva queda plantar. 


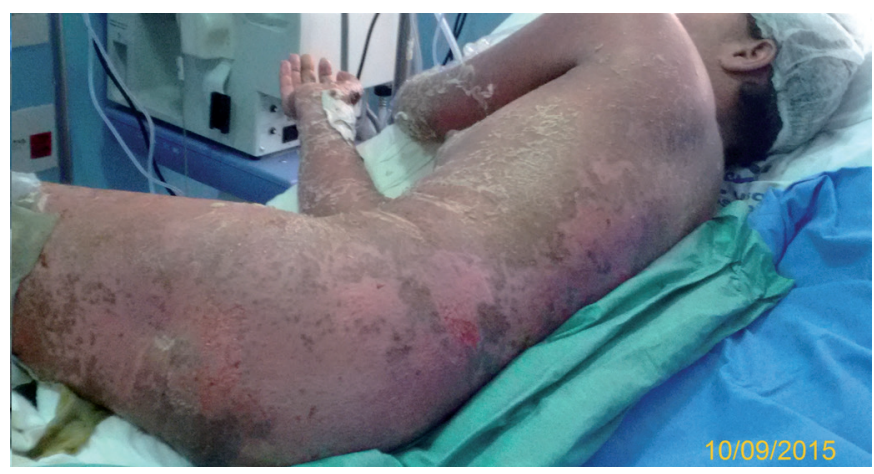

Figura 3: Evolução evidenciada na troca do curativo, após seis dias. Rio de Janeiro, RJ, Brasil, 2015

Fonte: Silva M FP, et al. Necrólise Epidérmica Tóxica associada ao Lúpus Eritematoso Sistêmico: um relato de caso.

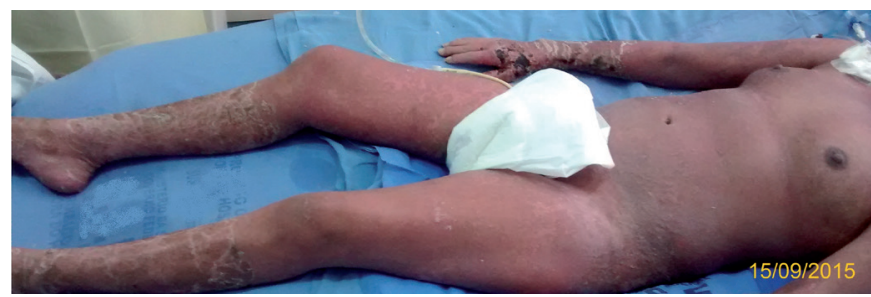

Figura 4: Evolução percebida na segunda troca do curativo, após cinco dias. Rio de Janeiro, RJ, Brasil, 2015

Fonte: Silva M FP, et al. Necrólise Epidérmica Tóxica associada ao Lúpus Eritematoso Sistêmico: um relato de caso.

Três dias após, a paciente havia recebido alta para a enfermaria onde se procedeu a troca de curativos na qual não foi necessário o uso de placas de hidrofibra, sendo utilizado PHMB para antissepsia e hidrogel como cobertura primária apenas em MSD e pé esquerdo, que ainda apresentavam necrose, porém com boa evolução. Os curativos subsequentes eram realizados pelos enfermeiros do setor mediante conduta deixada pela CTF e no dia 28/09 a paciente recebeu alta hospitalar com orientações da Comissão, nas condições que mostram a figura 5 .

Não foi exposto, em valores monetários, o custo com coberturas para o tratamento da paciente em questão, contudo podemos notar a provável redução de gastos quando analisada a relação entre o número de materiais utilizados inicialmente e no fim do tratamento, ou seja, percebe-se a diminuição do uso da placa de hidrofibra a cada troca de curativo, fato que não ocorreu com o uso da Sulfadiazina, onde se fez necessária a mesma quantidade diariamente.
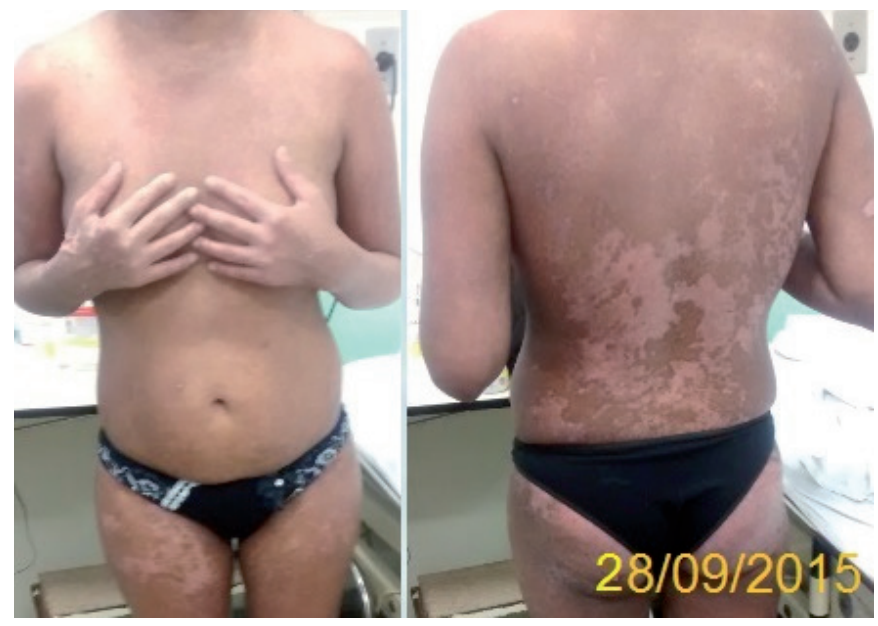

Figura 5: Completa epitelização - alta hospitalar. Rio de Janeiro, RJ, Brasil, 2015

Fonte: Silva M FP, et al. Necrólise Epidérmica Tóxica associada ao Lúpus Eritematoso Sistêmico: um relato de caso.

Tabela 1. Coberturas usadas na evolução do caso. Rio de Janeiro, RJ, Brasil, 2016

\begin{tabular}{|c|c|c|}
\hline DATA & CARACTERÍSTICAS & COBERTURA USADA \\
\hline 26 e $27 / 08 / 15$ & \multirow{5}{*}{$\begin{array}{l}\text { Exfoliação cutânea ( } \approx 80 \%) \text { derme extremamente friável, } \\
\text { vasculite em MSD com tecido necrótico e UPP em calcâneo } \\
\text { E com tecido necrótico }\end{array}$} & AGE \\
\hline 28/08/15 a 01/09/2015 & & $\begin{array}{l}\text { Sulfadiazina de prata a } 1 \% \text { (10 a } 12 \\
\text { bisnagas de } 50 \mathrm{~g} \text { por dia) }\end{array}$ \\
\hline 02/09/2015 & & AGE (11 frascos de $200 \mathrm{ml}$ ) \\
\hline 03/09/2015 & & $\begin{array}{l}\text { Sulfadiazina de prata a } 1 \% \text { (10 a } 12 \\
\text { bisnagas de } 50 \mathrm{~g} \text { por dia) }\end{array}$ \\
\hline 04/09/2015 & & $\begin{array}{l}\text { PHMB (05 frascos de } 350 \mathrm{ml})+86 \\
\text { placas de Hidrofibra } \mathrm{Ag}\end{array}$ \\
\hline $10 / 09 / 2015$ & $\begin{array}{l}\text { Epitelização parcial, glúteos e MMII pouco friáveis, vasculite } \\
\text { em MSD com tecido necrótico e UPP em calcâneo E com } \\
\text { tecido necrótico }\end{array}$ & $\begin{array}{l}\text { PHMB (02 frascos de } 350 \mathrm{ml})+18 \\
\text { placas de Hidrofibra Ag, Hidrogel } \\
\text { (vasculite e UPP) }\end{array}$ \\
\hline $15 / 09 / 2015$ & $\begin{array}{l}\text { Epitelização parcial, glúteos pouco friáveis, vasculite em } \\
\text { MSD com tecido de granulação e UPP em calcâneo E com } \\
\text { tecido necrótico }\end{array}$ & $\begin{array}{l}\text { PHMB }(\approx 20 \mathrm{ml})+03 \text { placas de } \\
\text { Hidrofibra Ag } \\
\text { Hidrogel (vasculite e UPP) }\end{array}$ \\
\hline $18 / 09 / 2015$ & $\begin{array}{l}\text { Epitelização total, vasculite em MSD com tecido de } \\
\text { granulação e UPP em calcâneo com tecido necrótico }\end{array}$ & $\begin{array}{l}\text { Creme de uréia } 10 \% \\
\text { PHMB + Hidrogel (vasculite e UPP) }\end{array}$ \\
\hline 28/09/2015 & UPP em calcâneo com tecido necrótico & $\begin{array}{l}\text { Creme de uréia } 10 \% \\
\text { PHMB + Hidrogel (vasculite e UPP) }\end{array}$ \\
\hline
\end{tabular}

Fonte: Silva MFP, et al. 2016 
Vale ressaltar que todos os curativos foram realizados com técnica e materiais estéreis e utilizando para limpeza das áreas afetadas solução fisiológica a 0,9\% e ainda, compressas e ataduras como coberturas secundárias.

\section{CONCLUSÃO}

Concluímos, portanto, que a hidrofibra teve eficácia comprovada no caso apresentado visto que: reduziu o tempo de internação da paciente com aceleração do processo de cicatrização; minimizou o sofrimento uma vez que a realização dos curativos diários era sinônimo de dor e necessitava do uso de sedativos e analgésicos; e deduz-se também que houve redução dos custos, pois o uso de hidrofibra aumentou o intervalo da realização dos curativos e dispensou o uso de medicações de alto valor monetário.

É evidente a importância do uso da cobertura adequada para cada demanda e se faz necessária uma maior atualização tanto dos profissionais da assistência quanto dos gestores institucionais no que diz respeito ao mercado de tecnologias para o tratamento de feridas, bem como a prática baseada em evidências, pois como foi dito por vezes neste relato, o uso adequado e da cobertura mais indicada pode ser efetivo e crucial para o melhor prognóstico do paciente.

\section{REFERÊNCIAS}

1. Cabral L, Diogo C, Riobom F, et al. Necrólise epidérmica tóxica (Síndrome de Lyell): uma patologia para as unidades de queimados. Acta Med Port. 2004; 17:129-140.

2. Assis MR, Baaklini CE. Como diagnosticar e tratar Lúpus Eritematoso Sistêmico. RBM Rev Bras Med [Internet]. 2009 [acesso em 18 dez 2015]. Disponível em: http://www. moreirajr.com.br/revistas.asp?fase=r003\&id_materia $=4087$

3. Smeltzer SC, Bare BG. Brunner \& Suddarth: Tratado de Enfermagem Médico-Cirúrgica.12a ed. Rio de Janeiro: Guanabara Koogan; 2011.

4. Ministério da Saúde (BR), Conselho Nacional de Saúde, Comissão Nacional de Ética em Pesquisa. Resolução n 466 , de 12 de dezembro de 2012. Dispõe sobre diretrizes e normas regulamentadoras de pesquisa envolvendo seres humanos. Diário Oficial da União [da] República Federativa do Brasil. 2013. 13;150(112 Seção 1):59-62

5. Guimarães MCSS, Geovanini T. Coberturas e novas tecnologias para o cuidado de feridas. In: Tratado de feridas e curativos: enfoque multiprofissional. Geovanini T, organizador. São Paulo: Rideel; 2014. p. 189-215.

6. Laboratórios B. Braun. Prontosan Solução [Internet]. Rio de Janeiro: Laboratórios B. Braun S/A Comunicação Corporativa. [acesso em 18 dez 2015]. Disponível em: http://www.bbraun.com.br/cps/rde/xchg/cw-bbraun-ptbr/hs.xsl/products.html?prid=PRID00001922

7. Santos Neto FC, Piccinini PS, Andary JM, Sartori LDP, Cancian LT, Uebel CO, et al. Abordagem cutânea na necrólise epidérmica tóxica. Rev. Bras. Cir. Plást.2017;32(1):128-134
8. Manhezi AC, Bachion MM, Pereira AL. Utilização de ácidos graxos essenciais no tratamento de feridas. Rev. bras. enferm. [Internet]. 2008 [acesso em 04 mai 2017]; 61(5):620-628. Disponível em: http://www.scielo.br/scielo.php?script=sci_ arttext \& pid=S0034-71672008000500015\&lng=en

9. Ferreira AM, Souza BMV, Rigotti MA, Loureiro MRD. Utilização dos ácidos graxos no tratamento de feridas: uma revisão integrativa da literatura nacional. Rev. esc. enferm. USP [Internet]. 2012 [acesso em 04 mai 2017]; 46(3):752-760. Disponível em: http://www.scielo.br/scielo.php?script=sci_ arttext \&pid=S0080-62342012000300030\&lng=en

10. Corrêa FB, Coltro PS, Farina Junior JA. Tratamento geral e das feridas na epidermólise bolhosa hereditária: indicação e experiência usando curativo de hidrofibra com prata. Rev. Bras. Cir. Plást.2016;31(4):565-572 